\title{
CLINICAL, RADIOGRAPHIC, AND HISTOLOGICAL EVALUATION OF THERACAL PULPOTOMY IN HUMAN PRIMARY TEETH
}

\author{
Mariem O. Wassel*, Dina H. Amin* and Amira S. Badran*
}

\begin{abstract}
Vital pulp therapy has always been a topic of debate in pediatric dentistry. Formocresol (FC) has been the most commonly used pulpotomy agent in primary teeth. Despite its high rate of clinical success, concerns about its safety have been raised in the literature. However there is lack of evidence that establishes the superiority of one type of treatment allowing for the replacement of FC. To evaluate the short term clinical, radiographic and histological success of TheraCal LC, in vital pulpotomy of primary molars, sixty mandibular primary molars indicated for vital pulpotomy were randomly distributed between test group that received TheraCal LC, and control group that received FC. After standardized pulpotomy and restoration of the teeth, clinical and radiographic follow up was carried out at 3 and 6 months. For the histological assessment, 5 cariously exposed primary molars that were planned for extraction due to orthodontic reasons received TheraCal LC vital pulpotomy. Teeth were extracted after 4 months, and prepared for histological evaluation. No clinical failure was recorded through the whole follow up period in both groups. Radiographic failure was (3.3\%) in both groups. One case in FC group showed internal root resorption and interradicular root resorption at 3 and 6 months, respectively. While, one case in the Theracal LC group had internal root resorption at 3 months. As for the histological findings, TheraCal LC was found to be relatively biocompatible, tissue response was found to be in the direction of repair. TheraCal LC was found to be as successful as FC over a 6 months period and might be an alternative to FC in vital pulp therapy
\end{abstract}

KEYWORDS: TheraCal LC; pulpotomy; primary teeth; clinical; radiographic; histologic evaluation.

\section{INTRODUCTION}

Dental caries is the most common chronic childhood disease that can easily progress to the dental pulp if left untreated ${ }^{[1]}$. In young children conservation of carious primary molars is essential to avoid loss of arch length, blocked out permanent teeth and eating difficulties. The treatment of carious lesions in the enamel and surface dentin in primary molars includes elimination of carious tissues and definite filling of the teeth. On the other hand, selecting the appropriate therapy may become controversial when the carious lesion is deeper or has exposed pulp tissues ${ }^{[2]}$.

\footnotetext{
* Department of Pediatric Dentistry and Dental Public Health, Faculty of Dentistry, Ain Shams University, Egypt
} 
Pulpotomy is the most common treatment for cariuosly exposed pulps in symptom-free primary teeth without evidence of radicular pathology ${ }^{[3]}$. The objective of this treatment is to remove the coronal inflamed tissue which usually contains microorganisms. Thus healing is allowed to take place at the entrance of the root canal with essentially healthy pulp tissues. Thereafter, the pulp stump could be treated with several agents leaving vital and uninfected radicular pulp tissues ${ }^{[4]}$. The ideal pulp dressing material after pulpotomy should leave the radicular pulp vital, healthy and enclosed within an odontoblastic lined dentin chamber ${ }^{[5]}$.

Due to its high clinical success rate (70\%-97\%), formocresol (FC) has been the "gold standard" for pulp therapy for the past 100 years ${ }^{[3,4]}$. Currently, concerns are raised regarding the use of $\mathrm{FC}$ due to the potentially mutagenic and carcinogenic effects of formaldehyde in humans ${ }^{[3,4,6]}$. Moreover, in contrast to the goal of preserving vital radicular pulp tissue, no healing attributes have been found with FC histologically. In fact, FC has been found to be cytotoxic, devitalizing the pulp and causing chronic inflammation and tissue necrosis ${ }^{[7,8]}$. Another concern is the fact that the 1:5 dilution of Buckley's FC that is most universally advocated for use in pediatric dentistry is not commercially available ${ }^{[9]}$.

Safety concerns about FC have led to other proposed treatment alternatives for pulp therapy such as mineral trioxide aggregate (MTA), ferric sulfate (FS), sodium hypoclorite, electrosurgery and laser pulpotomy. Those treatments have also been shown to have the potential to maintain radicular pulp vitality ${ }^{[10-12]}$.

According to several systematic reviews and meta-analysis, no strong evidence was found to identify one superior pulpotomy agent or technique. Analyses showed that MTA, which is calcium silicate based cement, is the first choice as an alternative to FC for primary molar pulpotomies. When using MTA is not feasible, FS which is a hemostatic agent was recommended as an alternative to $\mathrm{FC}$ as it was shown to have comparable success rates to FC with the advantages of eliminating systemic hazards maintaining pulp vitality, and lower cost compared to MTA ${ }^{[3,4,10]}$. However, some studies reported clinical and histological adverse effects of FS. ${ }^{[14-16]}$

In an attempt to make use of the benefits of MTA while decreasing its shortcomings, Biodentine ${ }^{\mathrm{TM}}$ (Septodont, Saint-Maurdes-fosses, France), which is a cement base of the same class as MTA with the advantages of faster setting time, higher strength properties, more pure calcium silicate content, was developed. ${ }^{[17,18]}$.

TheraCal LC (BISCO Dental Products, Schaumburg IL,USA) is a material that creates a new category of resin-modified calcium silicates. It is a light cured, resin based tricalcium silicate liner, which consists of tricalcium silicate particles in a hydrophilic monomer. The hydrophilic matrix provides significant calcium release creating an alkaline sustained environment that promotes dentin-pulp complex healing and regeneration making it a uniquely stable and durable material as a liner or base. It is radio-opaque and moisture tolerant and is indicated by its manufacturers to be used as a liner in direct and indirect pulp capping, as a protective base/liner under composites, amalgams, cements, and other base materials. It can be used as a replacement for calcium hydroxide, glass ionomer, resin modified glass ionomer, IRM/ZOE and other restorative materials. TheraCal LC performs as an insulator/barrier and protector of the dental pulpal complex ${ }^{[19]}$.

When the chemical-physical properties of TheraCal LC were compared to MTA and calcium hydroxide, TheraCal displayed significantly higher calcium-releasing ability and lower solubility than either MTA or calcium hydroxide. TheraCal was able to alkalinize the surrounding fluid initially to pH 10-11 (after 3hrs and for a period of 3days) and subsequently to $\mathrm{pH}$ 8-8.5 (7-14 days). The authors 
reported that the capability of TheraCal to be cured to a depth of $1.7 \mathrm{~mm}$ may avoid the risk of untimely dissolution. These properties offer major advantages in direct pulp-capping treatments ${ }^{[19]}$.

The significant calcium release provides reparative ions, creates a sustaining alkaline environment required to promote wound healing, provides immediate bond and sealing properties, and stimulates hydroxyl-apatite and secondary dentin formation within affected tissues. TheraCal LC has been approved as "apatite stimulating" by the US Food and Drug Administration as an interactive flowable resin that provides the early high alkalinity, (pH 10 to 11), required for pulpal healing but reverts back to a neutral $\mathrm{pH}$ after several days. It is self-sealing, which aids in antimicrobial activity with initial bonds to dentin to resist accidental airdrying removal. This high calcium release has been shown to be critical for the stimulation of apatite formation and secondary dentin bridge formation while providing a mechanical seal of the pulp. The ease of handling is another advantage of TheraCal as it is directly dispensed from a syringe dispenser, requiring no mixing, clicking or triturating and characterized by immediate setting. ${ }^{[20-23]}$

As the search for a pulp capping agent that is safe, biocompatible, and bioactive, has easy handling properties and reasonable cost is continuous, the current study sought to investigate the 6 months' clinical, radiographic and histological outcomes of TheraCal pulpotomy in human primary molars, and to compare the clinical and radiographic response of primary teeth to vital pulpotomy using TheraCal to Formocresol.

\section{MATERIAL AND METHODS}

A convenient sample of 60 mandibular primary molars was selected from 50 patients attending the out-patient clinic of the Pediatric Dentistry and Dental Public Health Department, Faculty of Dentistry, Ain Shams University.
The study was approved by the Ethical committee of Faculty of Dentistry, Ain Shams University (FDASU-REC R061607). A minimum sample size of 58 (29 in each group) was determined using Epicalc program version 1.02 assuming a power of $80 \%$ and alpha $=0.05$ and was based on number of teeth with possible radiographic success and failure, which was 52 and 4 teeth, respectively according to Vostatek et al, $2011^{[12]}$.

Participants were selected according to the following inclusion and exclusion criteria:

\section{- Inclusion criteria ${ }^{[12,24,25]}$}

4-7 years old children having restorable mandibular primary molars, with vital carious pulp exposures were selected. The selected children were cooperative with no underlying medical, learning or physical disabilities.

\section{- Exclusion criteria ${ }^{[12,24,25]}$}

Teeth were excluded if there was: any clinical evidence of pulp degeneration as history of spontaneous pain, pain on percussion, pathological mobility, periapical abscess, or sinus tract; any radiographic evidence of pulp degeneration such as pathologic external, or internal root resoprtion, periapical or interadicualr radiolucency, and pulp calcification, physiological root resorption of more than one third of the roots.

\section{Methods}

Prior to treatment, medical and dental histories, as well as clinical and radiographic examinations were carried out. Ethical consents and assents that were previously approved by the Ethical committee of Faculty of Dentistry, Ain Shams University were obtained from parents/legal guardians as well as participating children, respectively, before carrying out the clinical procedures.

The children were allocated into two groups alternatively as follows: group I (FC) $(n=30)$, group II (TheraCal LC) $(n=30)$. The participants in this trial were blinded as to their groups. 
Preoperative and postoperative as well as follow up periapical radiographs at 3 , and 6 months were obtained by standardized paralleling technique and exposure time of 0.25 seconds. An XCP film holder (Super Bite, Hawe Neos DentalSA, Switzerland) was used. Digital radiographs were obtained and scanned using size 0 phosphostimulable phosphor plates [X mind AC (de Gotzen, Italy) and FonaScaneo, phosphor plate scanner, respectively.

After administering local anesthesia [Mepivacaine HCL 2\% (Mepecaine-L, Alexandria Co. for Pharmaceuticals, Alexandria, Egypt)], and application of a rubber dam for isolation, a standardized pulpotomy procedure was carried out by the same operator for both groups. After achieving complete homeostasis using a salinemoistened cotton pellet that was placed over the orifices of the canals, the radicular pulp stumps were treated with one of the following medicaments; In group I, a cotton pellet that was moistened with Buckley's concentration (1:5 diluted bottle of FC that was prepared by the operator by mixing 3 parts of glycerin with 1 part of distilled water then adding 4 parts of this diluent to one part of formocresol $^{[9]}$ (Formacresol, PREVEST DenPro, Digiana, Jammu, India) was placed over the pulp stumps for 5 minutes. After removal of the cotton, the fixed pulp stumps were capped with reinforced zinc oxide and eugenol base (Zinconol, PREVEST DenPro, Digiana, Jammu, India). In group II, the pulp chamber was rinsed with sterile saline making sure no clot is present in the pulp chamber ${ }^{[25]}$. TheraCal was placed over the pulp stump in a $1 \mathrm{~mm}$ thickness, manipulated with a sterile probe to ensure a smooth surface that is free from air bubbles and light cured for 20 seconds. Thereafter, the rest of the pulp chamber was filled with reinforced zinc oxide and eugenol base (Zinconol, PREVEST DenPro, Digiana, Jammu, India).

Teeth in both groups were restored with stainless steel crowns (3M ESPE, St Paul, MN, USA) at the same visit, and an immediate postoperative radiograph was obtained. All patients were scheduled as needed to treat any other oral health problem. Parents were advised to contact the investigators between recalls if any adverse signs or symptoms occurred. The patients were recalled at 3 and 6 months for clinical and radiographic examination according to set criteria as follows ${ }^{[12,24,25]}$ : Absence of spontaneous pain; abscess or draining fistula; mobility; gingival inflammation; and faulty restoration. While, radiographic success criteria included absence of pathologic external root resorption; pathologic internal root resorption; inter-radicular bone destruction; widening of periodontal membrane space; and periapical radiolucency.

Clinical and radiographic failures were recorded in an evaluation sheet if the tooth presented one or more of the symptoms previously described. If no clinical signs or symptoms were evident, yet the patient revealed radiographic pathology, then only a "radiographic failure" was recorded. Clinical and radiographic evaluations were made by another operator that was blinded to the type of treatment.

For the histological evaluation, pulpotomy procedures were performed for five cariously exposed primary molars that were planned for extraction for orthodontic reasons. Teeth were extracted for space management, where there was a lack of space for premolars eruption due to premature loss of first primary molars leading to minor space loss. In such cases, placing a lingual holding arch to utilize the Leeway space for premolars' eruption as well as extraction of second primary molars to allow eruption of first premolars was needed.

Teeth met the exclusion and inclusion criteria of the study except that the age of children was higher and ranged from 8-9 years old. Teeth received TheraCal LC pulpotomy and were restored with high strength glass ionomer (Ketacfil plus Aplicap). Teeth were extracted after 4 months, preserved in $10 \%$ buffered formalin. After fixation, teeth were decalcified using $10 \%$ formic acid, and then they were embedded in paraffin wax, and prepared for 
hemotoxylin and eosine (H\&E) evaluation under light microscope (Olympus BX40; Olympus Co, Tokyo, Japan) for Inflammatory pulpal response, tissue disorganization, pulp necrosis, or reactionary dentin formation. ${ }^{[26]}$

\section{Statistical analysis}

Data were presented as frequencies and percentage values. Fisher's Exact test was used to compare between the two groups. The significance level was set at $\mathrm{P} \leq 0.05$. Statistical analysis was performed with IBM ${ }^{\circledR}$ SPSS ${ }^{\circledR}$ Statistics Version 20 for Windows.

\section{RESULTS}

\section{Clinical evaluation}

All cases in the two groups had no clinical failures through the whole follow up period. Recall of patients was $100 \%$ at 3 months, and 6 months for the $\mathrm{FC}$ group, and $96.7 \%$ at 3 months and 6 months for the TheraCal LC group (Table1). The data for clinical success at three months is not provided since no clinical failures were evident in both groups.

\section{Radiographic evaluation}

All cases in the two groups had no radiographic failures except for internal root resorption and inter- radicular bone resorption. In The FC group, one case $(3.3 \%)$ showed internal root resorption at 3 months and inter-radicular bone resorption at 6 months. While one case (3.3\%) in the TheraCal LC group had internal root resorption after three months follow up. Teeth showing radiographic failure were extracted at 6 months and a space maintainer was placed. Accordingly, there was no statistically significant difference between the prevalence of internal root resorption in the two groups (Tables 2, 3), (Figures 1,2).

TABLE (1): Clinical success of TheraCal LC and Formocresol after 6 months.

\begin{tabular}{|c|c|c|c|c|c|c|c|}
\hline \multirow{3}{*}{$\begin{array}{l}\text { Clinical Success } \\
\text { Absence of: }\end{array}$} & \multirow{3}{*}{6 Months } & \multicolumn{4}{|c|}{ Groups } & \multirow{2}{*}{\multicolumn{2}{|c|}{ Fisher's Exact test }} \\
\hline & & \multicolumn{2}{|c|}{ TheraCal LC } & \multicolumn{2}{|c|}{ Formocresol } & & \\
\hline & & $\mathbf{N}$ & $\%$ & $\mathbf{N}$ & $\%$ & $\mathbf{X}^{2}$ & P-value \\
\hline \multirow{2}{*}{ Spontaneous pain } & Drop out & 1 & 3.33 & 0 & 0.00 & \multirow{2}{*}{1.017} & \multirow{2}{*}{0.313} \\
\hline & Success & 29 & 96.67 & 30 & 100.00 & & \\
\hline \multirow{2}{*}{ Abscess/fistula } & Drop out & 1 & 3.33 & 0 & 0.00 & \multirow{2}{*}{1.017} & \multirow{2}{*}{0.313} \\
\hline & Success & 29 & 96.67 & 30 & 100.00 & & \\
\hline \multirow{2}{*}{ Mobility } & Drop out & 1 & 3.33 & 0 & 0.00 & \multirow{2}{*}{1.017} & \multirow{2}{*}{0.313} \\
\hline & Success & 29 & 96.67 & 30 & 100.00 & & \\
\hline \multirow{2}{*}{ Gingivitis } & Drop out & 1 & 3.33 & 0 & 0.00 & \multirow{2}{*}{1.017} & \multirow{2}{*}{0.313} \\
\hline & Success & 29 & 96.67 & 30 & 100.00 & & \\
\hline \multirow{2}{*}{ Faulty restoration } & Drop out & 1 & 3.33 & 0 & 0.00 & \multirow{2}{*}{1.017} & \multirow{2}{*}{0.313} \\
\hline & Success & 29 & 96.67 & 30 & 100.00 & & \\
\hline
\end{tabular}

*: Significant at $P \leq 0.05$. 
TABLE (2): Descriptive statistics and results of Fisher's Exact test for comparison between internal root resorption in the two groups.

\begin{tabular}{|c|c|c|c|c|c|c|}
\hline \multirow[t]{2}{*}{ Time } & \multirow[t]{2}{*}{$\begin{array}{c}\text { Internal Root } \\
\text { Resorption }\end{array}$} & \multicolumn{2}{|c|}{$\begin{array}{c}\text { TheraCal LC } \\
(\mathbf{n}=\mathbf{3 0})\end{array}$} & \multicolumn{2}{|c|}{$\begin{array}{l}\text { Formocresol } \\
\qquad(\mathbf{n}=\mathbf{3 0})\end{array}$} & \multirow[t]{2}{*}{$P$-value } \\
\hline & & $\mathrm{N}$ & $\%$ & $\mathrm{n}$ & $\%$ & \\
\hline \multirow[t]{3}{*}{3 months } & Yes & 1 & 3.3 & 1 & 3.3 & \multirow[t]{3}{*}{1.000} \\
\hline & No & 28 & 93.3 & 29 & 96.7 & \\
\hline & Drop-out & 1 & 3.3 & 0 & 0.0 & \\
\hline \multirow[t]{3}{*}{6 months } & Yes & 1 & 3.3 & 1 & 3.3 & \multirow[t]{3}{*}{1.000} \\
\hline & No & 28 & 93.3 & 29 & 96.7 & \\
\hline & Drop-out & 1 & 3.3 & 0 & 0.0 & \\
\hline
\end{tabular}

*: Significant at $P \leq 0.05$.

TABLE (3): Inter-radicular bone resorption in both groups.

\begin{tabular}{|c|c|c|c|c|c|c|c|}
\hline \multirow[t]{2}{*}{ Time } & \multirow{2}{*}{$\begin{array}{l}\text { Inter-radicular } \\
\text { bone resorption }\end{array}$} & \multicolumn{2}{|c|}{$\begin{array}{l}\text { TheraCal LC } \\
\qquad(\mathbf{n}=\mathbf{3 0})\end{array}$} & \multicolumn{2}{|c|}{$\begin{array}{l}\text { Formocresol } \\
\qquad(\mathbf{n}=\mathbf{3 0})\end{array}$} & $\mathbf{X}^{2}$ & $P$-value \\
\hline & & $\mathbf{N}$ & $\%$ & $\mathbf{n}$ & $\%$ & \multirow{4}{*}{$\mathrm{a}$} & \multirow{4}{*}{$\mathrm{a}$} \\
\hline \multirow[t]{3}{*}{3 months } & Yes & 0 & 0 & 0 & 0 & & \\
\hline & No & 29 & 96.6 & 30 & 100 & & \\
\hline & Drop-out & 1 & 3.3 & 0 & 0 & & \\
\hline \multirow[t]{3}{*}{6 months } & Yes & 0 & 0 & 1 & 3.3 & \multirow[t]{3}{*}{0.983} & \multirow[t]{3}{*}{0.508} \\
\hline & No & 29 & 96.6 & 29 & 96.6 & & \\
\hline & Drop-out & 1 & 3.3 & 0 & 0 & & \\
\hline
\end{tabular}

a: can't be computed as variable is constant. *: Significant at $P \leq 0.05$.

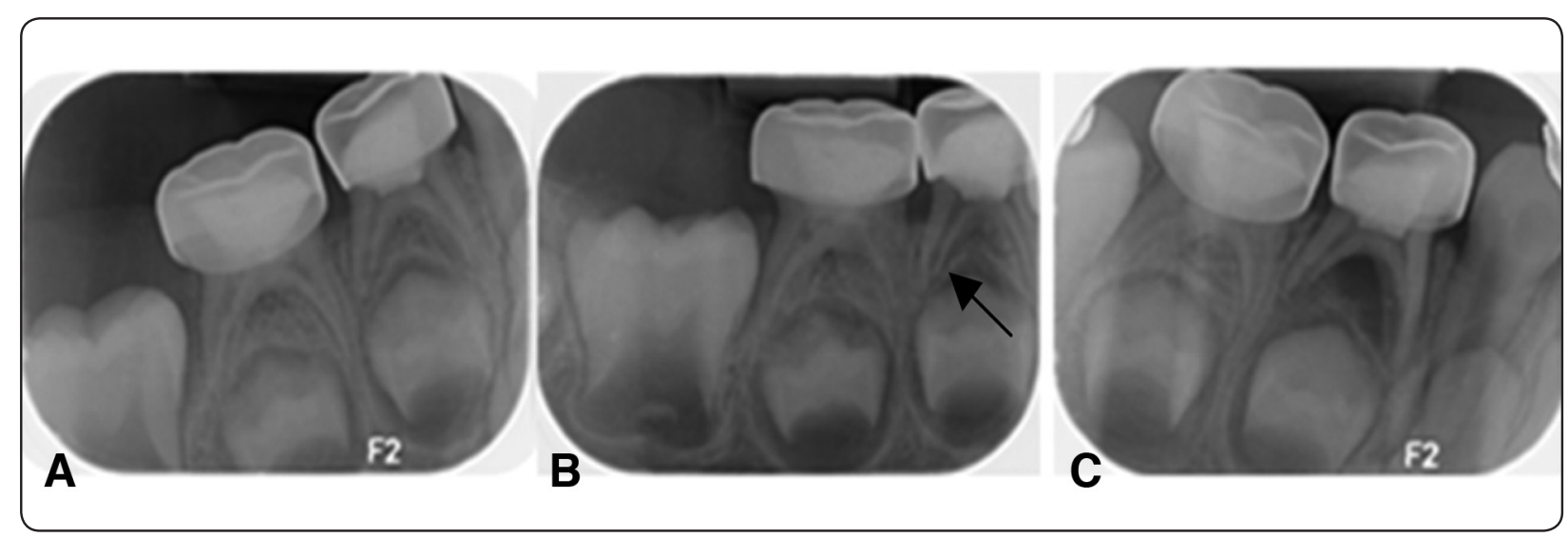

Fig. (1) Formocresol pulpotomy in lower right first primary molar; (a) postoperative radiograph, (b) at 3 months showing internal root resorption (arrow), (c) at 6 months showing inter-radicular bone resorption. 


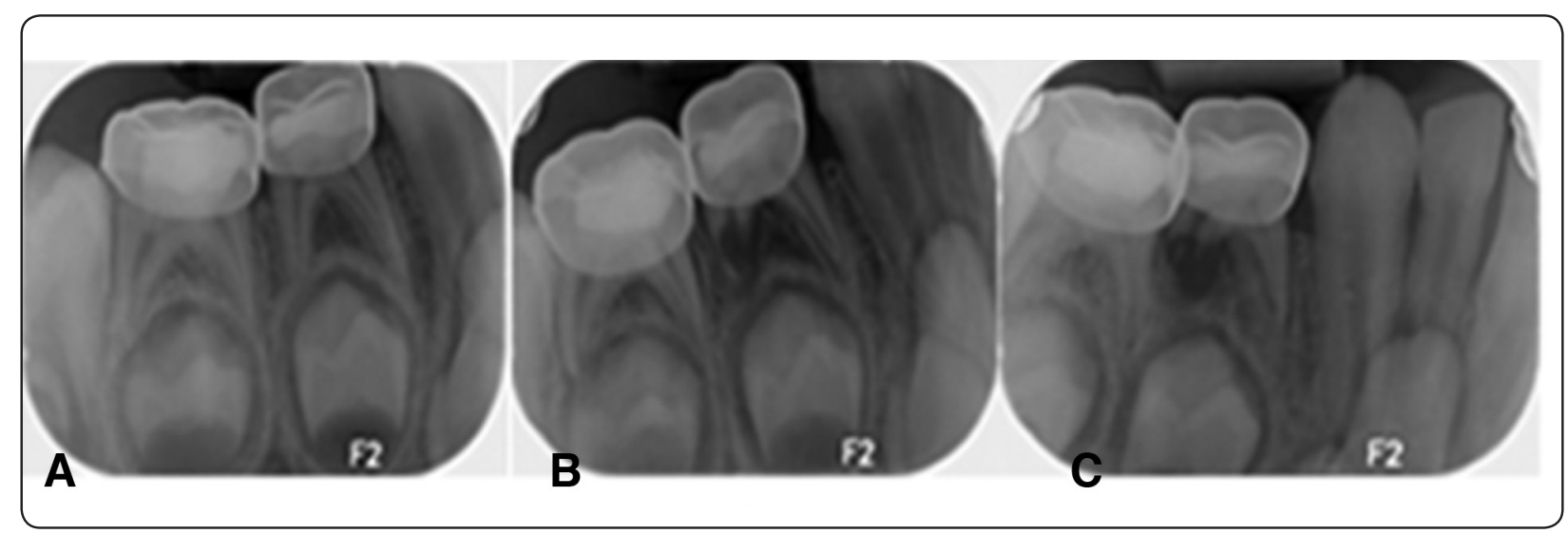

Fig. (2) TheraCal Pulpotomy in lower right first primary molar; (a) postoperative radiograph, (b) at 3 months showing internal root resorption, (c) at 6 months showing internal root resorption.

\section{Histological evaluation}

Chronic inflammatory cell infiltration with varying densities was seen. Hard tissue formation (foci of calcification, dentinoid tissue and osteodentin) were frequently noticed. There was disruption of odontoblasts in some areas, yet undifferentiated mesenchymal cells were seen along the root sides forming osteodentin. No polymorphnuclear leucocytes were found (Figures 3-6).

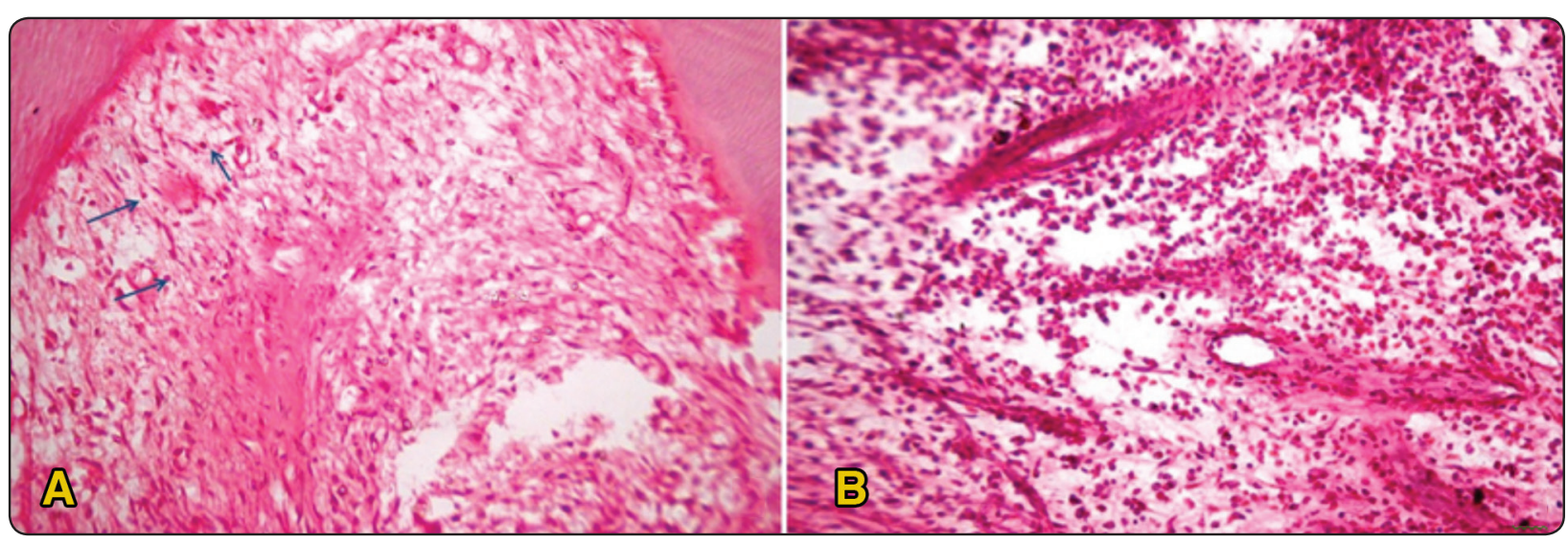

Fig. (3) H\&E section showing chronic inflammatory cell infiltration with varying densities;(a)mild infiltration of chronic inflammatory cells (blue arrows ) (40X), (b) abundance of inflammatory cells(40X). 


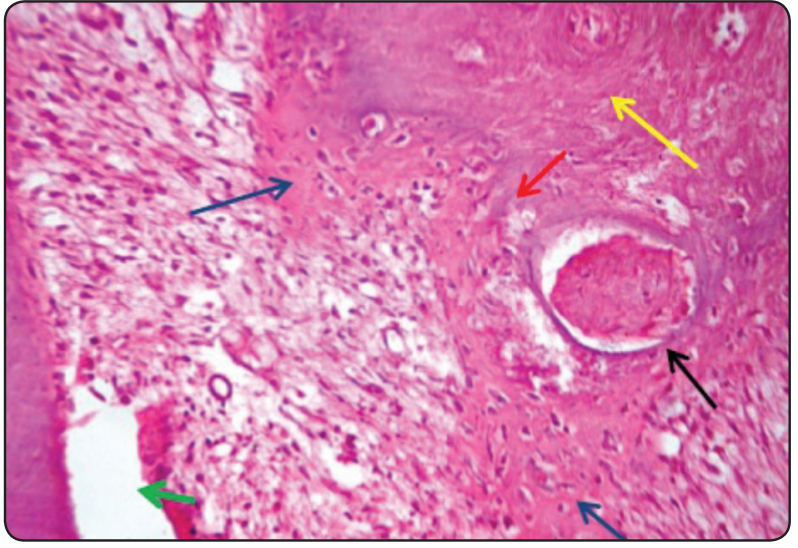

Fig(4) H\&E section showing interruption in odontoblastic layer (green arrow), new hard tissue formation with entrapped cells consistent with osteodentin (blue arrows), basophilic (violet) linear deposits denoting calcification on top of osteodentin (red arrow), dentinoid tissue without entrapped cells (yellow arrow), ring calcification along the wall of a blood vessel (black arrow),(40 X).

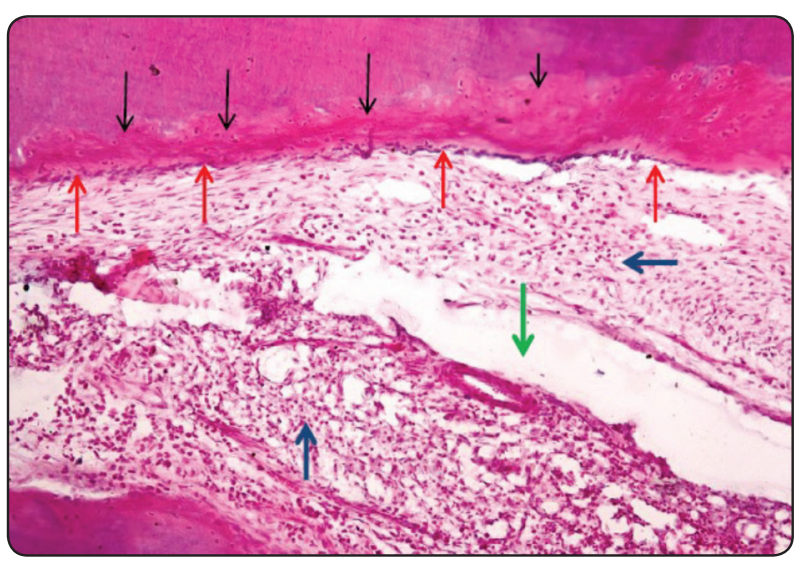

Fig. (5) Newly deposited osteodentin along the sides of the root that is sharply demarcated from root dentin (black arrows). Cellular rimming of undifferentiated mesenchymal cells that transformed to dentin forming cells (red arrows). Abundant chronic inflammatory cells (blue arrows) with partial necrosis in the central pulp (green arrow), (20X).

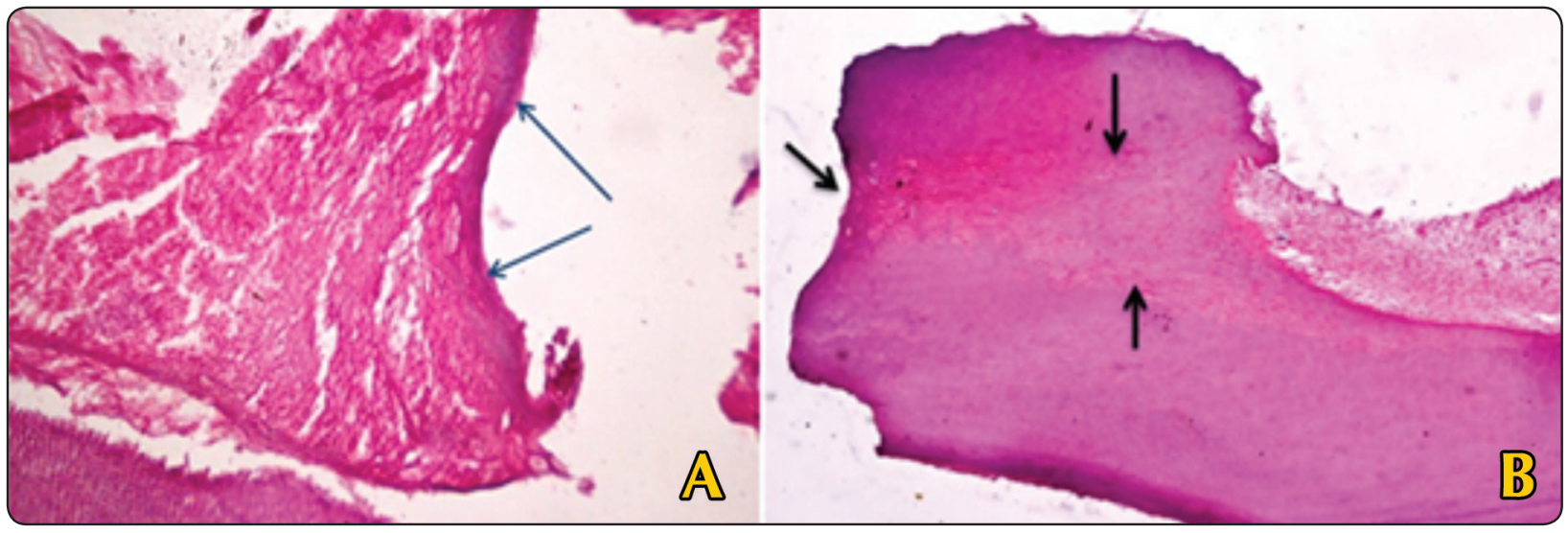

Fig. (6) H\&E section showing; (a) linear basophilic and acellular deposits indicating partial calcific bridging at one root entrance (blue arrows) (40X), (b) Complete obliteration of root apex with osteodentin (black arrows) (10X).

\section{DISCUSSION}

The current clinical,radiographic and histological investigation was conducted to determine the potential effectiveness of Theracal LC as a reliable replacement for $\mathrm{FC}$ when undertaking pulpotomy in primary teeth.

Very few clinical studies as well as some animal studies have been conducted on the use of the TheraCal LC on pulps in primary teeth, ${ }^{[19,23,26]}$ leaving little evidence in the literature concerning the clinical performance and success of TheraCal LC in pulpotomized primary teeth. Griffin, $2012^{\text {[27] }}$ applied TheraCal to traumatically exposed mature central incisors and reported favorable clinical symptoms for 10 months.

Similarly, and based on the results achieved in the present study, it seems that TheraCal LC could be used successfully to treat primary teeth with reversible pulpitis. All cases in the two groups had no clinical failures through the whole follow up 
period. These findings are particularly important in that it appears to be one of few times that TheraCal LC has ever been applied in the primary molar tooth pulpotomy in children.

Several different pulpal responses to different treatment methods and medicaments have been reported following their use in pulp treated primary teeth. The two most common radiographic findings reported in the literature are internal root resorption and inter-radicular bone destruction. ${ }^{[12-14]}$. Similarly In the current study, only internal root resorption and inter- radicular bone destruction were encountered. Internal root resorption was detected in only one case $(3.3 \%)$ in the FC group after 3 months, and inter-radicular bone resorption was detected in the same case after 6 months and one case $(3.3 \%)$ in the ThraCal group showed internal root resorption after three months follow up. Accordingly, the radiographic success was $96.7 \%$ for both $\mathrm{FC}$ and TheraCal (Tables 3,4), (Fig. 2, 3). The radiographic and clinical success, in the present study fall within the range of previously published data that have ranged between $73 \%$ and $96 \%$ for FC and other medicaments ${ }^{[3,12,13,14]}$.

Previous investigations suggested that similar failures were the result of inadequate coronal seal, inflammatory response from the zinc oxide eugenol base, inconsistency in techniques from utilizing multiple operators, or improper selection of the teeth ${ }^{[3-5]}$. In the present study, patients were selected with age range 4 to 7 years old to achieve good patient cooperation and to confirm that the physiologic root resorption will not interfere with the recorded results as one of the confounding factors. Also all treated teeth were restored with suitable- sized stainless steel crowns to provide adequate seal against immediate and long-term microleakage along the entire restoration interface. To avoid and minimize failure due to improper diagnosis, teeth selection was done according to strict clinical and radiographic criteria, which ensured to a fair extent - the absence of irreversible changes in the dental pulp, and this was reflected on our results where no clinical failures were reported during the whole study period. Standardization of the technique was achieved by using a standardized paralleling technique to avoid any distortion in the vertical dimension and to provide reproducible images. Treatment of selected teeth was performed by a single operator with the same technique in a single visit.

However, unfortunately, the limitation of this study was the 6-months follow-up of our patients that although ensured patients commitment in the follow up visits, yet it was rather short for evaluating the long term outcome of pulpotomy and success rate, accordingly further studies are needed to judge the preference of TheraCal LC to Formocresol in the long term. Yet this study might provide a basis for further studies in this field advocating a longterm follow-up and more participants.

Histological evaluation of pulp treated teeth using TheraCal LC in animals had shown interesting and promising results that encouraged its use in human teeth. Cannon, et al, $2014^{[23]}$ reported significantly more frequent hard tissue bridge formation and less pulpal necrosis with TheraCal LC than the GIC and light cure calcium hydroxide groups in primates. Lee, et al, $2015^{[26]}$ evaluated the histological effects of various MTAs on pulp tissues for a 4-week period and came up with the conclusion that calcium ions released from MTAs are known to play an important role in odontoblastic differentiation although the precise mechanisms underlying MTA-induced odontoblastic differentiation are not completely understood. However, they recommended the implementation of further researches for evaluating the long-term effects of the pulpotomy agents. Moreover, they noted that the findings of their study in dogs may not directly correspond to those in humans. Therefore, clinical trials using human teeth are necessary for a more accurate understanding 
of the materials. In the current study a thorough histological evaluation was performed following a period of four months of application of TheraCal LC in human pulp treated primary teeth. The results of the present study revealed that TheraCal LC caused chronic inflammation with varying intensities which is a normal response to a foreign material. Tissue response was found to be in the direction of repair revealing osteodentin, dentinoid tissue and calcific foci formation. Though there were areas of disruption in ondontoblastic cell layer, yet stimulation of undifferentiated mesenchymal cells to form osteodentin along dentinal walls was seen. Absence of polymorphnuclear leucocytes, a sign of acute inflammation, is in favor of TheraCal LC which also correlates to clinical findings where no abscess formation was evident.

\section{CONCLUSION}

Within the limitations of the present study, it was concluded that TheraCal LC is a relatively biocompatible material with comparable clinical and radiographic success rates over 6 months to Formocresol .

\section{REFERENCES}

1- Dean JA, Avery DR, McDonald RE. Dentistry for the child and adolescents; $9^{\text {th }}$ ed, Mosby INC, 2011.

2- Rivera N, Reyes E, Mazzoaui S, Moron A. Pulpal therapy for primary teeth; J Dent Child 2003;70:71-73.

3- Fuks AB. Vital pulp therapy with new materials for primary teeth: New directions and treatment prespectives. Pediatr Dent 2008;3:211-219.

4- Lin P-Y, Chen H-S, Wang Y-H, Tu Y-K. Primary molar pulpotomy: Asystematic review and network metaanalysis. J Dent 2014;42:1060-1077.

5- Ranly DM, Garcia Godoy F. Reviewing pulp treatment for primary teeth; J Am Dent Assoc 1991; 122(10):83-85.

6- Ranly DM, Garcia-Godoy F. Current and potential pulp therapies for primary and young permanent teeth. J Dent 2000; 28:153-61.
7- Srinivasan V, Patchett CL, Waterhouse PJ. Is there life after Buckley's formocresol? Part I: A narrative review of alternative interventions and materials. Int J Pediatr Dent 2006;16:117-27.

8- Sabbarini J, Mounir M, Dean J. Histological evaluation of enamel matrix derivative as a pulpotomy agent in primary teeth. Pediatr Dent 2007;29:475-9.

9- King SA, McWhorter AG, Seale NS. Concentration of formocresol used by pediatric dentists in primary tooth pulpotomy. Pediatr Dent 2002;24:157-159.

10- Stringhini Junior E , Vitcel MEB, Oliveira LB. Evidence of pulpotomy in primary teeth comparing MTA, calcium hydroxide, ferric sulphate, and electrosurgery with formocresol. Eur Arch Paediatr Dent 2015; 16(4):303-312.

11- Uloopi KS, Vinay C, Ratnaditya A, Satya gopal A, Mrudula KJ, Chandrasekhar Rao R. Clinical evaluation of low level diode laser application for primary teeth pulpotomy. JCDR 2016;10(1):67-70.

12- Vostatek SF, Kanellis MJ, Weber-Gasparoni K, Gregorsok RL. Sodium Hypochlorite Pulpotomies in Primary Teeth: A Retrospective Assessment. Pediatr Dent 2011; 33:327-32.

13- Akcay M. The effect of Sodium Hypochlorite application on the success of calcium hydroxide and Mineral Trioxide Aggregate pulpotomies in primary teeth. Pediatr Dent 2014; 36(4): 316-321.

14- Casas MJ, Layug MA, Kenny DJ, Johnston DH, Judd PL. Two-year outcome of primary molar ferric sulfate pulpotomy and root canal therapy. Pediatr Dent 2003;25:97-102.

15- Salako N, Joseph B, Ritwik P, Salonen J, John P, Junaid TA. Comparison of bioactive glass, mineral trioxide aggregate, ferric sulfate, and formocresol as pulpotomy agents in rat molars. Dent Traumatol 2003;19:314-320.

16- Vargas KG, Packham B. Radiographic success of ferric sulfate and formocresol pulpotomies in relation to early exfoliation. Pediatr Dent 2005; 27:233-237.

17- Rajasekharan S, Martens L, Vandenbulcke J, Jacquet W, Bottenberg P, Cauwels R. Efficacy of three different pulpotomy agents in primary molars - A randomised control trial. Int Endod J 2017 Mar;50(3):215-228.

18- Shayegan A, Jurysta C, Atash R, Petein M. Biodentine used as a pulp- capping agent in primary pig teeth. Pediatr Dent 2012; 34(7): 202-208. 
19- Gandolfi MG, Siboni F, Prati C. Chemical-physical properties of TheraCal, a novel light-curable MTA-like material for pulp capping. Int Endodont J 2012;45(6):571-9.

20- Dickens SH, Flaim GM, Schumacher GE, Eichmiller FC, Schafer DR, Rutherford RB. Preclinical effectiveness of a novel pulp capping material. J Endod 2010;36:1222-1225.

21- Gandolfi MG, Siboni F, Taddei P, Modena E, Prati C. Apatite-forming ability of Theracal pulp-capping material. J Dent Res 2011(Spec Iss A):Abstract number 2520, 2011

22- Okabe T, Sakamoto M, Takeuchi H, Matsushima K. Effects of $\mathrm{pH}$ on mineralization ability of human dental pulp cells. J Endod 2006;32: 198-201.

23- Cannon M, Gerodias N, Viera A, Percinoto C, Jurado R. Primate pulpal healing after exposure and TheraCal application. J Clin Pediatr Dent 2014;38(4):333-337.
24- Vargas KG, Packham B, Lowman D. Preliminary evaluation of sodium hypochlorite for pulpotomies in primary molars. Pediatric Dentistry 2006;28:511-7.

25- Agamy HA, Bakry NS, Mounir MM, Avery DR: Comparison of mineral trioxide aggregate and formocresol as pulp-capping agents in pulpotomized primary teeth. Pediatric Dentistry 2004;26:302-309.

26- Lee H, Shin Y, Kim SO, Lee HS, Choi HJ, Song JS. Comparative Study of Pulpal Responses to Pulpotomy with ProRoot MTA, RetroMTA, and TheraCal in Dogs' Teeth. J Endod 2015;41(8):1317-24.

27- Griffin JD Jr. Utilizing bioactive liners. Stimulating posttraumatic dentin formation Dent Today 2012.; 31(10):132, 134-136. 